\title{
ESTUDO DA FUSIBILIDADE DAS CINZAS DE CARVÕES EM FUNÇÃO DA COMPOSIÇÃO QUÍMICA E MINERALÓGICA
}

\author{
Maurício Covcevich Bagatini ' \\ Maria Luisa Formoso Ghiggi ${ }^{2}$ \\ Eduardo Osório ${ }^{3}$ \\ Antônio C. F. Vilela ${ }^{4}$ \\ Roberto $\mathrm{Cruz}^{5}$ \\ Guilherme Defendi ${ }^{6}$
}

\section{Resumo}

Considerando a intensa utilização do carvão no setor siderúrgico e energético, é indispensável o conhecimento mais aprofundado da matéria inorgânica desse insumo. Nesse trabalho busca-se relacionar as fases minerais contidas nas cinzas de carvão ao seu respectivo comportamento de fusibilidade. Foram selecionados para esse estudo três diferentes tipos de carvão. Inicialmente foi feita uma identificação da matéria mineral dos carvões através da DRX. As cinzas obtidas com a queima dos carvões foram caracterizadas através das técnicas de FRX e DRX. As propriedades reológicas das cinzas foram estudadas através de testes de fusibilidade. Como ferramenta auxiliar aos testes de fusibilidade também foi utilizado o MEV. Verificou-se a presença de diferentes fases cristalinas entre as amostras. Os ensaios de fusibilidade também evidenciaram o comportamento distinto entre as cinzas. Para os carvões em estudo, constatou-se que as fases ilita e quartzo tendem a baixar a temperatura de amolecimento. As fases ricas em alumínio tendem a elevar a temperatura de fusão das amostras, enquanto que a presença dos óxidos de $\mathrm{K}, \mathrm{Na}, \mathrm{Ca}$ e $\mathrm{Mg}$ nas fases formadas contribuem para a fluidez das cinzas.

Palavras-chave: Cinzas; Fusibilidade; Composição química; Composição mineralógica.

\section{COAL-ASH FUSIBILITY ANS ITS RELATION TO CHEMICAL AND MINERALOGICAL COMPOSITION}

\begin{abstract} the presence of $\mathrm{K}, \mathrm{Na}, \mathrm{Ca}$ e $\mathrm{Mg}$ oxides in the formed phases contribute to the ashes fusibility.

Key words: Ash; Fusibility; Mineral composition; Chemical composition.

\section{INTRODUÇÃO}

Considerando a intensa utilização do carvão no setor siderúrgico e energético, o conhecimento detalhado da matéria inorgânica do carvão e do seu respectivo comportamento em temperaturas elevadas é de grande relevância. Durante a combustão, a matéria

\footnotetext{
' Engenheiro Metalúrgico, Mestrando do PPGEM, Laboratório de Siderurgia - Lasid / UFRGS

${ }^{2}$ Engenheira Metalúrgica LASID / Centro de Tecnologia / Escola de Engenharia / UFRGS

${ }^{3}$ Prof. Dr. LASID / Centro de Tecnologia / Escola de Engenharia / UFRGS

${ }^{4}$ Prof. Dr.-Ing LASID / Escola de Engenharia / Centro de Tecnologia / UFRGS

${ }^{5} \mathrm{MSc}$, Especialista de Altos-fornos, ArcelorMittal Tubarão, Vitória

${ }^{6}$ Especialista de Altos-fornos, ArcelorMittal Tubarão, Vitória
}

Due to the great use of coal in the ironmaking plants and powerstations, it is very important to have a deeper knowledge of inorganic matter of this raw material. This study aims to identify the mineral phases responsible for the fluidity behavior of the coal ashes. Three differents types of coal were selected for this study. At first an identification of the mineral matter of the coals was done through the XRD. The ashes from the coals combustion were characterized through XRF chemical analysis and XRD. The rheologic properties were studied by the ash fusion tests in oxidant atmosphere. As an auxiliary tool in the fusibility tests, SEM was also used. The presence of different crystaline phases among the samples via XRD was also observed. The fusibility tests showed the different behaviour of the ashes in their respective temperatures of softening and fusibility. Concerning the studied coals, the illite and quartz phases tend to decrease the softening temperature. The phases rich in aluminium tend to increase the fusion temperature of the samples, whereas

inorgânica do carvão se transforma em cinzas que podem se depositar sobre as superfícies de transferência de calor nos sistemas de combustão das caldeiras termelétricas, reduzindo a eficiência da transferência de calor. ${ }^{(1)} \mathrm{Na}$ produção de ferro primário, as cinzas resultantes da injeção de carvão 
nas ventaneiras podem se acumular sobre o coque e paredes da região inferior do alto-forno, promovendo a queda de permeabilidade dos gases e do metal líquido que prejudica a estabilidade do processo. ${ }^{(2,3)}$

As cinzas remanescentes da combustão do carvão consistem de uma mistura complexa de fases cristalinas e amorfas sem um ponto de fusão definido. ${ }^{(4)}$ Essa parcela inorgânica do carvão se caracteriza por agregar em sua composição uma grande diversidade de óxidos, entre eles $\mathrm{SiO}_{2}, \mathrm{Al}_{2} \mathrm{O}_{3}, \mathrm{Fe}_{2} \mathrm{O}_{3}, \mathrm{CaO}, \mathrm{MgO}, \mathrm{TiO}_{2}, \mathrm{~K}_{2} \mathrm{O}$ e $\mathrm{Na}_{2} \mathrm{O} .{ }^{(5)}$

A previsão do comportamento de fusibilidade das cinzas a partir da composição química é considerada inadequada, sendo que a forma na qual os elementos estão combinados é de maior relevância. ${ }^{(4-6)}$. As principais fases minerais encontradas nas cinzas do carvão são: quartzo, argilominerais, feldspatos, silicatos, hematita e anidrita. ${ }^{(4)}$

Os testes de fusibilidade das cinzas de carvão também auxiliam na compreensão do comportamento desse material em altas temperaturas, indicando os estágios de amolecimento e fusão. ${ }^{(4,7)}$ Menores temperaturas de fusibilidade estão relacionadas a proporções crescentes de minerais fluxantes tais como sulfatos, silicatos e minerais óxidos como anidrita, plagioclásio ácido, feldspato alcalino, silicato de cálcio e hematita presentes em altas temperaturas. Elevadas temperaturas de fusibilidade resultam de baixas concentrações de minerais fluxantes e grandes concentrações de minerais refratários tais como quartzo, caulinita e rutilo contido nas cinzas. ${ }^{(4)}$

O presente estudo busca avaliar o comportamento da matéria mineral em temperaturas elevadas para diferentes carvões usados em $\mathrm{PCl}$, visando identificar as fases relacionadas às temperaturas de fusibilidade das cinzas.

\section{MATERIAIS E MÉTODOS}

\section{I Caracterização dos Carvões}

Três diferentes tipos de carvão foram selecionados para o estudo. Inicialmente o material foi quarteado para obter uma amostra representativa na realização das análises e após esta etapa se fez a moagem do carvão nas granulometrias requeridas para cada técnica analítica. A análise imediata dos carvões I, 2 e 3 encontra-se na Tabela I.

Tabela I. Análise imediata dos carvões I, 2 e 3.

\begin{tabular}{ccccc}
\hline Carvões & $\mathbf{M V}_{\text {bs }}(\%)$ & $\mathbf{C z}_{\text {bs }}(\%)$ & $\mathbf{U}(\%)$ & $\mathbf{C ~ f i x o ~}_{\text {bs }}(\%)$ \\
\hline $\mathrm{I}$ & 37,94 & 9,58 & 6,10 & 52,48 \\
2 & 36,73 & 10,33 & 3,92 & 52,94 \\
3 & 13,81 & 8,8 & 1,69 & 77,38 \\
\hline
\end{tabular}

A partir do carvão in natura foram realizadas análises de difração de raios $X$ no intuito de conhecer as fases minerais presentes nos carvões.

\subsection{Obtenção e Caracterização das Cinzas}

Para obtenção das cinzas dos carvões, realizou-se a combustão completa na temperatura de $850^{\circ} \mathrm{C}$ com isoterma de duas horas em forno mufla.
As cinzas foram submetidas às técnicas de análise descritas a seguir com suas respectivas finalidades:

- fluorescência de raios x (FRX): identificar e quantificar as proporções dos elementos maiores contidos na amostra;

- difração de raios $\mathrm{x}$ : identificar as fases cristalinas presentes acima de $5 \%$ no material (esse valor pode sofrer variações em função da cristalinidade da fase); e

- teste de fusibilidade: indicar o comportamento dos componentes inorgânicos do carvão durante o aquecimento. Foram determinadas as temperaturas críticas (temperatura de amolecimento, temperatura de hemiesfera e temperatura de fluidez) em função das deformações específicas decorrentes da transição de fase nos corpos de prova produzidos com as cinzas (indicadas na Figura I).
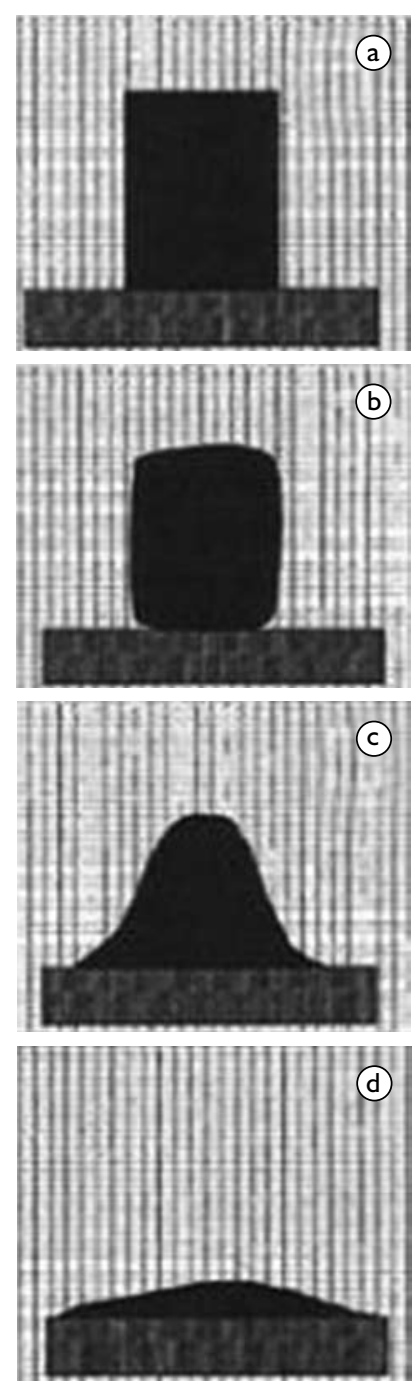

Figura I. a) amostra no início do teste; b) amolecimento; c) hemiesfera; e d) ponto de fluidez. 
Esses testes foram realizados em um microscópio de aquecimento de acordo com a norma DIN 5I730, com um corpo de prova cilíndrico ( $\mathrm{L}=3 \mathrm{~mm}$ e $\mathrm{d}=3 \mathrm{~mm}$ ) em atmosfera oxidante (ar). ${ }^{(9)}$ No presente estudo, se deu maior ênfase as temperaturas de amolecimento e de fluidez. A temperatura de amolecimento é indicada quando se tem a alteração da superfície, arredondamento das arestas ou inchamento do corpo de prova, enquanto na temperatura de fluidez, o corpo de prova fundido, espalha-se sobre a base de sustentação; ${ }^{(9)}$ e

- MEV (Miscroscopia Eletrônica de Varredura): verificar a morfologia das cinzas submetidas ao aquecimento na temperatura de $1.300^{\circ} \mathrm{C}$ e $1.500^{\circ} \mathrm{C}$ e resfriadas em nitrogênio líquido. Esta metodologia foi aplicada com a finalidade de auxiliar os resultados obtidos pelo teste de fusibilidade.

\section{RESULTADOS E DISCUSSÕES}

\section{I Caracterização dos Carvões}

Na Figura 2 encontram-se os resultados obtidos pela análise de DRX referente aos carvões in natura. Os minerais identificados no carvão I são quartzo e caulinita. $O$ difratograma do carvão 2 mostra que além do quartzo e da caulinita, identificados no espectro do carvão I, a dolomita também se mostra presente na amostra do carvão 2. O carvão 3 apresenta um espectro diferenciado dos demais carvões, sendo que dos minerais identificados nos difratogramas anteriores, o único em comum foi a caulinita. Destaca-se a não identificação do mineral quartzo para esse carvão. $O$ espectro referente ao carvão 3 evidencia ainda a presença de argila e da siderita, minerais não detectados nos demais carvões. É importante salientar que o elevado halo amorfo apresentado nas três amostras indica a grande quantidade de material amorfo, relativo a matéria orgânica do carvão. ${ }^{(1,4)}$
Como visto nos resultados da Figura 2, comprova-se a existência de uma matéria mineral diferenciada entre os carvões.

\subsection{Caracterização da Cinza}

\subsection{Análise química por FRX}

A composição química das cinzas foi obtida via $F R X$ e o resultado dessa análise, expresso na forma de óxidos, se encontra na Tabela 2.

A partir da Tabela 2 verifica-se que os óxidos majoritários são semelhantes nas amostras, sendo esses o óxido de silício, o óxido de alumínio e o óxido de ferro. A soma dos percentuais dos óxidos de silício e alumínio, corresponde à no mínimo $76 \%$ (cinzas do carvão 3). Porém, existem relevantes diferenças quanto aos teores desses óxidos entre as amostras. Observa-se que no caso das cinzas do carvão I, o óxido de silício é altamente preponderante frente ao óxido de alumínio.

O óxido de ferro apresenta-se como o terceiro maior componente das cinzas, sendo que na amostra 3 a percentagem desse composto chega atingir 8,3\%. Entre os compostos minoritários nota-se que os teores dos óxidos de cálcio e magnésio variam significativamente nas três amostras, onde a soma destes compostos é nitidamente inferior para o carvão I. Os óxidos encontrados via FRX estão de acordo com os minerais encontrados nos carvões via DRX.

\subsubsection{Difração de raios $X$}

Os resultados de DRX para as cinzas dos três carvões são mostrados nos difratogramas das
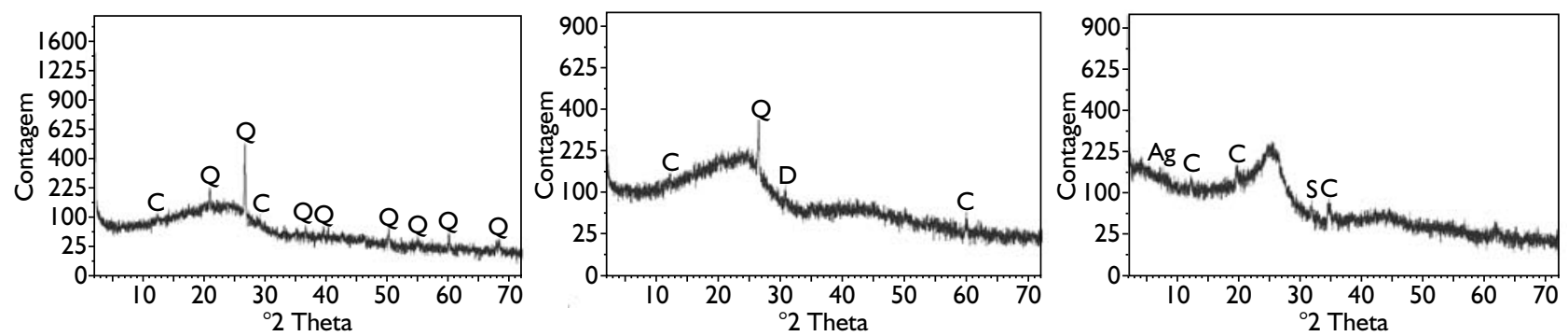

Figura 2. Espectros de $D R X$ referentes aos carvões I, 2 e 3 in natura respectivamente. $C$ - caulinita: $\left.A_{2} \mathrm{Si}_{2} \mathrm{O}_{5}(\mathrm{OH})_{4}\right] ; \mathrm{Q}-\mathrm{quartzo}: \mathrm{SiO}{ }_{2} ; \mathrm{D}$ - dolomita: $\mathrm{CaMg}(\mathrm{CO})_{3}$; $\mathrm{Ag}$ - argila: $\mathrm{K}\left(\mathrm{Si}_{2} \mathrm{Al}\right) \mathrm{Al}_{2} \mathrm{O}_{10}(\mathrm{OH})$; e $\mathrm{S}$ - siderita: $\mathrm{FeCO}_{3}$.

Tabela 2. Composição química das cinzas via $F R X\left(P . F=\right.$ Perda ao fogo a $\left.1.000^{\circ} \mathrm{C}\right)$.

\begin{tabular}{cccccccccccc}
\hline Componentes & $\mathbf{S i O}_{2}$ & $\mathbf{A l}_{2} \mathbf{O}_{3}$ & $\mathbf{F e}_{\mathbf{2}} \mathbf{O}_{3}$ & $\mathbf{M g O}$ & $\mathbf{C a O}$ & $\mathbf{N a}_{2} \mathbf{O}$ & $\mathbf{K}_{\mathbf{2}} \mathbf{O}$ & $\mathbf{T i O}_{2}$ & $\mathbf{P}_{2} \mathbf{O}_{5}$ & $\mathbf{S O}_{3}$ & $\mathbf{P . ~ F}_{1}$ \\
\hline Carvão I & 70,70 & 18,47 & 5,87 & 0,86 & 0,92 & 0,33 & $\mathrm{I}, 4 \mathrm{I}$ & $0,6 \mathrm{I}$ & 0,26 & 0,72 & 0,65 \\
Carvão 2 & 59,13 & 20,97 & 7,66 & 2,70 & 2,68 & 0,44 & $\mathrm{I}, 8 \mathrm{I}$ & 0,82 & 0,10 & 2,97 & $\mathrm{I}, 30$ \\
Carvão 3 & 42,00 & 34,20 & 8,30 & $\mathrm{I}, 10$ & 4,00 & 0,72 & 2,00 & $\mathrm{I}, 84$ & $\mathrm{I}, 90$ & $\mathrm{I}, 70$ & $\mathrm{I}, 77$ \\
\hline
\end{tabular}


Figuras 3, 4 e 5. Identificou-se a partir do espectro das cinzas do carvão I (Figura 5) as fases minerais quartzo, hematita, anidrita e anfibólio. O difratograma referente às cinzas do carvão 2 é mostrado na Figura 4. Nesta amostra foram detectadas fases semelhantes às cinzas do carvão I (quartzo, hematita e anidrita), entretanto, em vez do anfibólio encontrou-se a fase ilita. Através do difratograma da Figura 7, novas fases foram identificadas para cinzas do carvão 3. Surgem as presenças do plagioclásio e da fluorapatita além das demais fases em comum com as cinzas do carvão 2 .

Como visto, diferentes proporções de óxidos encontrados na análise química por FRX proporcionam a formação de diferentes fases cristalinas nas cinzas, conforme indicam os espectros das Figuras 3, 4 e 5.

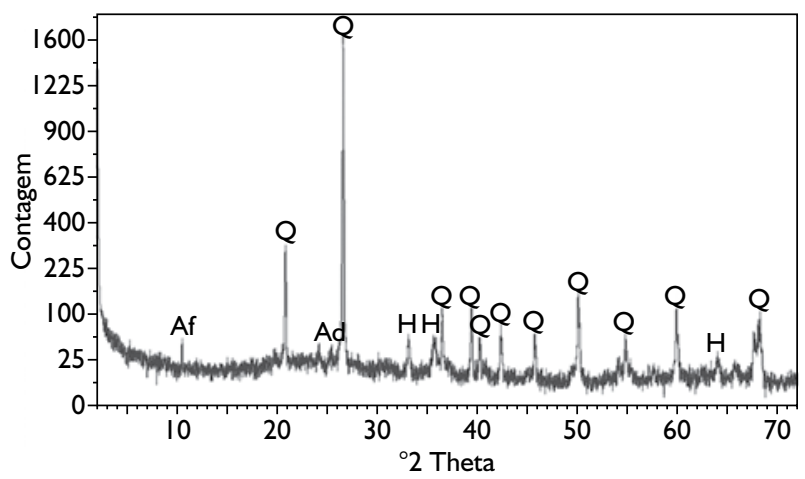

Figura 3. Espectro de DRX das cinzas do carvão I.

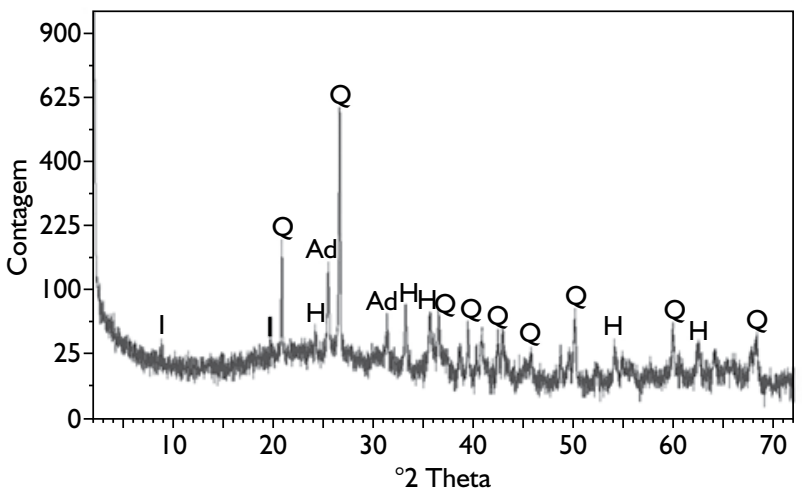

Figura 4. Espectro de DRX das cinzas do carvão 2.

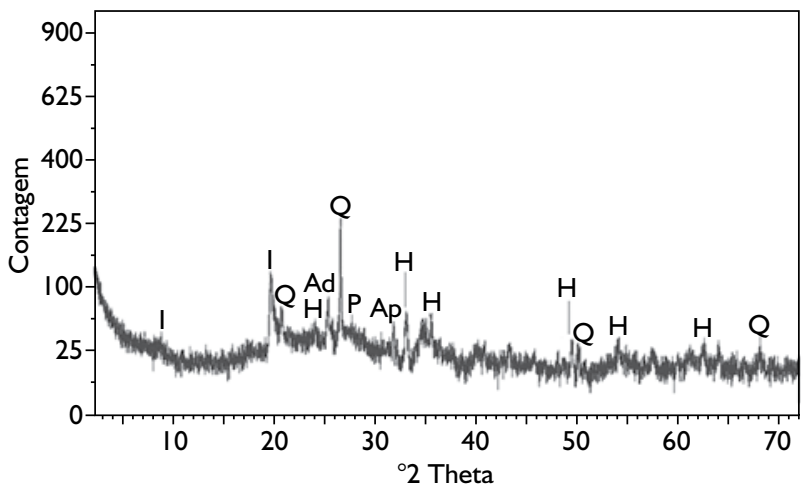

Figura 5. Espectro de DRX das cinzas do carvão 3.
Para a fase quartzo é possível fazer uma análise semi-quantitativa a partir da intensidade dos picos (eixo das ordenadas) medida nos difratogramas. A relação proporcional aproximada de quartzo obtida a partir desse método é da ordem de 7 para as cinzas do carvão I, 2,5 para as cinzas do carvão 2 e I para as cinzas do carvão 3. Portanto, verifica-se que as cinzas do carvão I apresentam teores mais elevados dessa fase com relação às demais amostras.

A quantidade menos expressiva de quartzo no carvão 3 também se confirma pelo fato dessa fase não ter sido identificada no carvão in natura. Nessa mesma amostra, a ocorrência da fase fluorapatita possivelmente está relacionada aos mais elevados teores dos óxidos de cálcio e fósforo (Tabela I) apresentados por esse carvão. O plagioclásio, também identificado na cinza do carvão 3, se deve provavelmente ao maior teor de sódio identificado pela análise de FRX.

Os teores mais elevados do elemento $K$ (Tabela I) nas cinzas dos carvões 2 e 3 justificam o pico referente à fase ilita nas Figuras 6 e 7.

Portanto, as diferenças entre as fases encontradas na Figura 2 referente aos carvões in natura, se refletem nos distintos espectros apresentados para as respectivas cinzas. É importante salientar que as fases anidrita e hematita são consideradas fases secundárias, ou seja, decorrentes de transformações da combustão e não da estrutura mineralógica original do carvão. Já a fase mineral caulinita encontrada nos carvões in natura sofre desidratação e se transforma em metacaulinita (amorfa) após a combustão, impossibilitando sua identificação nos espectros referente às cinzas. ${ }^{(1,4,8)}$

\subsubsection{Testes de fusibilidade}

$\mathrm{Na}$ Tabela 3 são mostrados os resultados obtidos pelos Testes de Fusibilidade para as cinzas dos três tipos de carvão.

Estes testes permitem determinar as temperaturas referentes aos principais estágios de amolecimento e fusão, que também estão vinculados às propriedades de fluidez das amostras. ${ }^{(4)}$

A temperatura de amolecimento corresponde à deformação inicial relacionada às transformações minerais como reações sólidosólido e amolecimento e fusão de fases minerais localizadas. ${ }^{(4)}$

As cinzas do carvão 2 e 3 apresentam a menor e a maior temperatura de amolecimento, respectivamente. Normalmente, esta temperatura está relacionada à fusão inicial da ilita $\left(1.000^{\circ} \mathrm{C}-1.300^{\circ} \mathrm{C}\right)$ e ao amolecimento inicial 
Tabela 3. Ensaio de fusibilidade para as cinzas dos três tipos de carvão.

\begin{tabular}{ccccc}
\hline Fusibilidade ( $\left.{ }^{\circ} \mathbf{C}\right)$ & $\mathbf{T}_{\text {amolecimento }}$ & $\mathbf{T}_{\text {hemiesfera }}$ & $\mathbf{T}_{\text {fluidez }}$ & $\mathbf{T}_{\text {fluidez }}-\mathbf{T}_{\text {amolecimento }}$ \\
\hline Carvão 1 & 1.380 & 1.520 & 1.600 & 220 \\
Carvão 2 & 1.280 & 1.380 & 1.440 & 160 \\
Carvão 3 & 1.480 & 1.540 & 1.580 & 100 \\
\hline
\end{tabular}

do quartzo $\left(\sim 1.300^{\circ} \mathrm{C}\right)$, quando presentes na composição mineralógica das cinzas. ${ }^{(4)} \mathrm{A}$ menor temperatura de amolecimento identificada para as cinzas do carvão 2 possivelmente está relacionada à presença das fases minerais quartzo e ilita. Entretanto, as cinzas do carvão I, enriquecidas de quartzo, apresentam uma temperatura de amolecimento superior às cinzas do carvão 2 . Sugere-se como justificativa desse comportamento, a presença da fase mineral anfibólio em vez da ilita nesta amostra. No caso da amostra 3, o baixo teor de quartzo e o elevado teor de alumínio, sugerem uma maior importância da fase refratária metacaulinita de alto ponto de fusão, ${ }^{(4,5,8)}$ o que deve justificar a maior temperatura de amolecimento, apesar da presença da ilita.

Como técnica auxiliar ao teste de fusibilidade das cinzas, verificou-se a morfologia das amostras via MEV (Microscopia Eletrônica de Varredura) em temperaturas próximas aos estágios de amolecimento e fusão das amostras.

A morfologia das amostras aquecidas a $1.300^{\circ} \mathrm{C}$, seguidas de resfriamento com nitrogênio líquido, é apresentada na Figura 6.
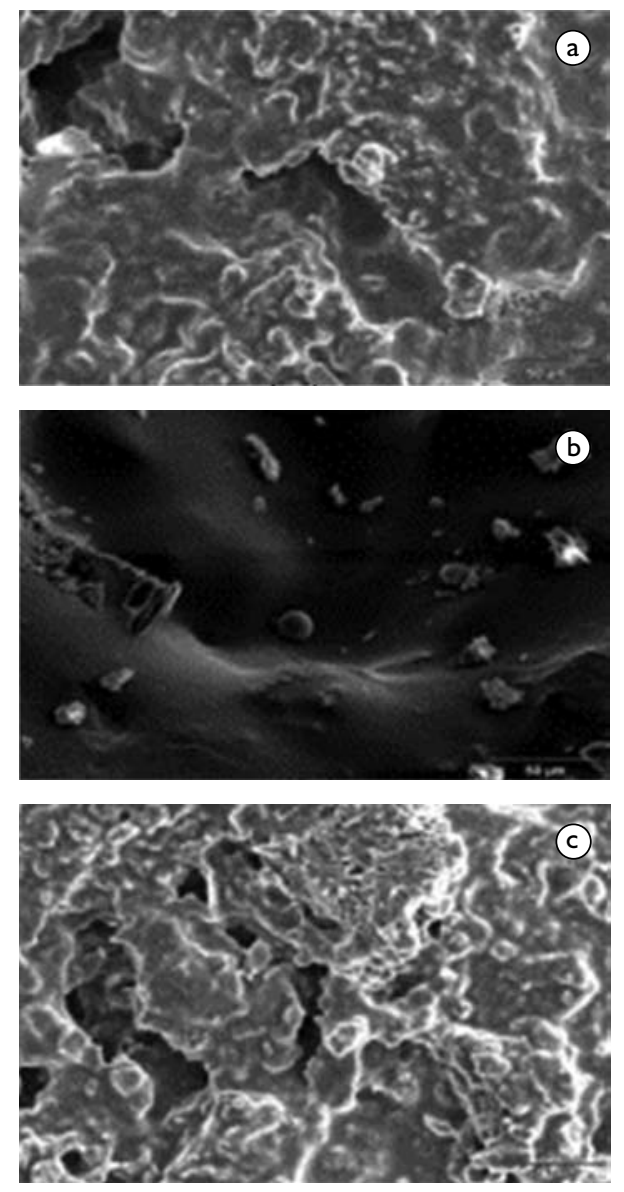

Figura 6. Morfologia das cinzas a $1.300^{\circ} \mathrm{C}$ (aumento de $500 \mathrm{x}$ ), a) carvão I; b) carvão 2; e c) carvão 3.
Quando aquecidas na temperatura de $1.300^{\circ} \mathrm{C}$, percebe-se que as cinzas dos carvões I e 3 (Figuras 6a e 6c, respectivamente) apresentam poucas regiões fundidas, sendo a fase sólida visivelmente preponderante. Já as cinzas do carvão 2 (figura 6b) exibem uma parcela majoritária de fase líquida nesta temperatura, confirmando a menor temperatura de amolecimento indicada pelo teste de fusibilidade. Nota-se que mesmo em temperatura inferior a de amolecimento, algumas partículas já se encontram no estado líquido, como é o caso das amostras I e 3. Esta observação está de acordo com os resultados obtidos por Vassilev ${ }^{(4)}$ e Huffman. ${ }^{(8)}$

A temperatura de fluidez no teste de fusibilidade está relacionada aos teores das fases minerais refratárias como o quartzo e a metacaulinita, que escoam com maior dificuldade com relação às demais fases encontradas nas cinzas. Geralmente, longos intervalos de fusão são característicos de cinzas enriquecidas em minerais refratários e curtos intervalos correspondem às cinzas com teores mais elevados de feldspato, plagioclásio ácido, hematita e anidrita. ${ }^{(4,5,8)}$

Para as cinzas do carvão I, verificou-se na Tabela 3 a maior temperatura de fluidez entre as amostras analisadas, resultando em um intervalo de $220^{\circ} \mathrm{C}$ desde a temperatura de amolecimento $\left(T_{\text {fluidez }}-T_{\text {amolecimento }}\right)$. Possivelmente esse comportamento se deve ao elevado teor de quartzo apresentado pela amostra I via FRX e DRX. O menor intervalo de temperatura entre a ocorrência dos fenômenos de amolecimento e fluidez $\left(100^{\circ} \mathrm{C}\right)$ foi encontrado para as cinzas do carvão 3. O baixo teor de quartzo e a presença das fases minerais anidrita, hematita, plagioclásio ácido indicados na composição mineralógica da amostra 3 , provavelmente justificam o curto intervalo encontrado nestas cinzas no teste de fusibilidade. Nas cinzas do carvão 2, a menor temperatura de amolecimento, associada ainda à presença das fases anidrita e hematita, devem contribuir para a mais baixa temperatura de fluidez destas cinzas.

A morfologia, obtida com o MEV, das respectivas cinzas aquecidas a $1.500^{\circ} \mathrm{C}$ (temperaturas próximas a $T_{\text {fluidez }}$ ) e resfriadas com nitrogênio líquido são apresentadas na Figura 7.

Como mostrado na Figura 7, na temperatura de $1.500^{\circ} \mathrm{C}$ todas as amostras indicaram a ocorrência do estado líquido como fase predominante. Observa-se que as cinzas do carvão I (Figura 7a) apresentam morfologia similar às cinzas do carvão 2 (Figura 7b), mesmo sem esta ter atingido a temperatura de fluidez $\left(T_{f}=1.600^{\circ} \mathrm{C}\right)$. Esse resultado justifica-se pelo fato de que as 

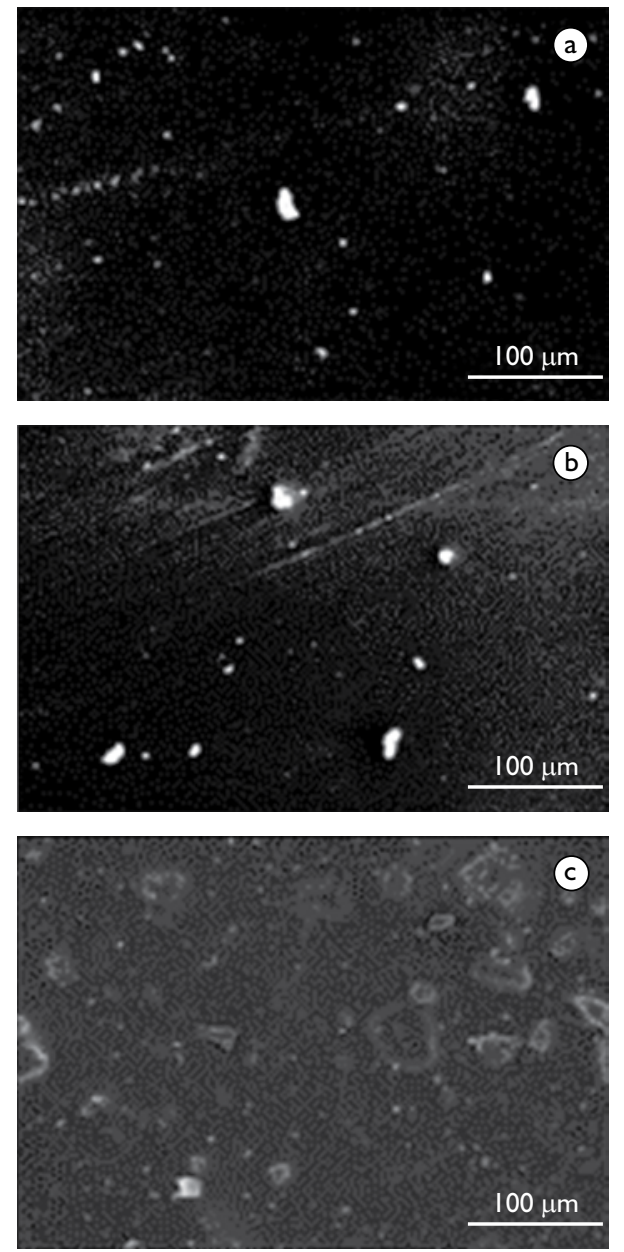

Figura 7. Morfologia das cinzas a $1.500^{\circ} \mathrm{C}$ (aumento de 300x), a) carvão I; b) carvão 2; e c) carvão 3.

temperaturas indicadas no teste de fusibilidade são relacionadas às propriedades de escoamento das amostras.

Para as cinzas do carvão 3 (Figura 7c) verifica-se ainda a presença de partículas no estado sólido, embora em menores proporções quando comparada à morfologia obtida a $1300^{\circ} \mathrm{C}$. A presença de fases contendo elevado alumínio provavelmente deu origem a partículas de alto ponto de fusão na amostra 3 , como ilustrado na Figura 7c.

De um modo geral, grandes quantidades de fases minerais com alto ponto de fusão causam um aumento nas temperaturas de fusibilidade, enquanto que quantidades elevadas de fases com baixo ponto de fusão diminuem esses valores de temperatura. Porém esse fato não é sempre verdadeiro, pois muitas dessas fases minerais das cinzas sofrem transformações e interações em altas temperaturas originando novas fases com diferentes pontos de fusão. (2)

\section{CONCLUSÕES}

Para os carvões em estudo, verificou-se a significativa influência da composição química e mineralógica sobre o comportamento físico de amolecimento e fluidez das cinzas remanescentes da combustão.

A partir dos resultados obtidos constatou-se que:

- a presença das fases minerais ilita e quartzo nas cinzas contribuem para mais baixas temperaturas de amolecimento, como é o caso do carvão 2;

- elevados teores de quartzo na composição mineralógica tendem a dificultar a fluidez das cinzas, como é possível perceber com o carvão I;

- elevados teores de óxido de alumínio nas cinzas sugerem uma maior presença de fases com elevado ponto de fusão, que implicam em temperaturas de amolecimento e de fluidez mais altas, caso do carvão 3;

- não foi possível verificar a influência da hematita nas propriedades de fusibilidade das cinzas, pois nas amostras em estudo a presença dessa fase se mostrou similar quantitativa e qualitativamente; e

- óxidos minoritários como $\mathrm{CaO}, \mathrm{MgO}$, $\mathrm{Na}_{2} \mathrm{O}$ e $\mathrm{K}_{2} \mathrm{O}$ também indicam uma influência significativa no comportamento de fusibilidade das cinzas, sendo que $o$ aumento desses contribuem na formação de fases com elevada fluidez, como por exemplo a ilita, a anidrita e o plagioclásio.

Entretanto, como regra geral, é necessário salientar após esse estudo de fusibilidade das cinzas, que a realização de uma análise crítica sobre todos os elementos contidos nas cinzas é indispensável, de forma que estes podem originar uma grande variação de fases com propriedades bastante distintas.

Este trabalho compreende a fase inicial de um estudo com abordagem mais ampla, que tem o objetivo de validar novas técnicas de análise para uma maior variação de matérias-primas. 


\section{REFERÊNCIAS}

I BRYERS, R. W. Fireside slagging, fouling, and high-temperature corrosion of heat-transfer surface due to impurities in steam-raising fuels. Progress in Energy and Combustion Science, v. 22, n. I, p. 29-I 20, 1996.

2 ICHIDA, M.; ORIMOTO, T.; TANAKA, T.; KOIZUMI, F. Behavior of pulverized coal ash and physical property of dripping slag under high pulverized coal injection operation. ISIJ International, v. 4I, n. 4, p. 325-32, 200 I.

3 KALKREUTH, W.; BORREGO, A.G.; ALVAREZ, A. D.; MENENDEZ, R.; OSÓRIO, E.; RIBAS, M; VILELA, A; CARDOZO ALVES, T.C. Exploring the possibilities of using Brazilian Bubbituminous coalsfor blast furnace pulverized fuel injection. Fuel, v. 84, n.6, p. 763-72, Apr. 2005.

4 VASSILEV, S. V.; KITANO, K, TAKEDA, S.; TSURUEB, T. Influence of mineral and chemical composition of coal ashes on their fusibility. Fuel Processing Technology, v. 45, n. I, p. 27-5I, Oct.1995.

5 VARGAS S.; FRANDSEN, F. J.; DAM-JOHANSEN, K. Rheological properties of high-temperature melts of coal ashes and other silicates. Progress in Energy and Combustion Science, v. 27, n.3, p. 237-429, Mar. 2001.

6 VAN DYK. J. C.; BAXTER, L. L.; VAN HEERDEN, J. H. P.; COETZER, R.L.J. Chemical fractionation tests on South African coal sources to obtain species-specific information on ash fusion temperatures (AFT). Fuel, v. 84, n. 14-5, p. 1768-1777, Sept. 2005.

7 GUPTA, S.K.; WALL, T.F.; CREELMAN, R.A.; GUPTA, R.P. Ash fusion temperatures and the transformations of coal ash particles to slag. Fuel Processing Technology, v. 56, n. I-2, p. 33-43, July 1998.

8 HUFFMAN, G. P.; HUGGINS, F. E.; DUNMYRE, G. R. Investigation of the high-temperature behavior of coal ash in reducing and oxidizing atmospheres. Monroeville: US Steel Corporation, 1980.

9 DEUTSCHES INSTITUT FÜR NOMUNG. DIN 5 I 730: Testing of solid fuels - Determination of fusibility of fuel ash. Berlin, 200-?.

Recebido em: 10/01/07

Aceito em: 19/07/07

Proveniente de: SEMINÁRIO DE REDUÇÃO DE MINÉRIO DE FERRO E MATÉRIAS PRIMAS, 36., 2006, Ouro Preto. São Paulo: ABM, 2006. 